\title{
The cost benefit analysis of level crossing safety measures
}

\author{
R. Ben Aoun, E.-M. El Koursi \& E. Lemaire \\ University of Lille North of France, INRETS, France
}

\begin{abstract}
Even though the general safety level of rail transport is quite satisfactory compared to road transport, a problem still persists, that of level crossings (LCs). The fact is that road users' behavior plays a large part in accidents where most of them do not occur following a failure of the railway system but are due to individuals' behavior. Knowing this, the Rail Optimization Safety Analysis (ROSA) project intends to identify several safety measures through a cost benefit analysis (CBA) in order to enhance the safety level at LCs on the French and German railway systems. The choice of leading a CBA is not random. Indeed, it allows comparisons between all the possible alternatives to aid the decision makers to be able to invest in the most profitable safety measure. However, it is very difficult to include all the effects of all the possible safety options. This is why the results have to be interpreted with caution.
\end{abstract}

Keywords: cost benefit analysis, safety measure, railway, level crossing, $L C$.

\section{Introduction}

A cost benefit analysis (CBA) aspires to estimate the profitability of a project from the whole community point of view by quantifying the willingness-to-pay or the willingness-to-accept. The willingness-to-pay - or the willingness-toaccept - is the stated amount that an individual is willing to pay - or to accept in compensation for a loss or a diminution of its utility. For instance, the willingness-to-pay for human life informs society about the importance that the governments grant for human life (e.g. Bellavance et al. [3]). In general, a CBA takes place in four stages: i) the qualitative and quantitative assessment, ii) the identification of all the possible effects for all the foreseen options and from the point of view of different groups of concerned individuals, iii) the monetary 
valuation of all these impacts so as to, iv) select the most suited solution for the community. This last stage is based on three crucial selection criteria: the net present value (NPV), which is the difference between the updating benefits and the updating costs; the internal rate of return, which is the rate for which the net present value is equal to zero; and, the benefit to cost ratio, which is the discounted benefits divided by the discounted costs.

Within this framework, the actualization is very important in the sense where it reflects the arbitrary choices between the present and the future generations which the community makes. Actually, the future costs and benefits have to be discounted according to a recommended rate (e.g. Rodgers and Leland [23]). To be consistent and to be able to compare several results from a few CBAs (e.g. Treasury Board of Canada Secretariat [30]; National Institute of Health [21]; Ministry of the Equipment, the Transport, the Accommodation, the Tourism and the Sea [20]), several cost benefit analysis guidelines recommend that each CBA must specify the point of view of the analysis, adopt a standardized step to be able to compare all the different alternatives by updating the obtained results, determine the willingness-to-pay or the willingness-to-accept if the market prices are distorted (or refer to the literature for reference values) and endorse the results with a sensitivity analysis. This last stage is very important because the sensitivity analysis indicates if the results are reliable or not. For this, each sensitivity analysis has to take into account the following guidelines (NIH IT projects [21]):

- A parameter is not considered to be sensitive if it requires a decrease of $50 \%$ or an increase of $100 \%$ to cause a change in the selected alternative;

- A parameter is considered to be sensitive if a change between $10 \%$ and $50 \%$ causes a change in the selected alternative;

- A parameter is considered to be very sensitive if a change of $10 \%$ or less causes a change in the selected alternative.

Moreover, to be thorough and strengthen the results, the CBA has to take into account the same parameters for the two different countries. Indeed, one of the stakes of the CBA is to make a harmonization and to compare the results between the two countries so that the definitions of parameters are elementary. Actually, to harmonize the results, the European countries must have the same definitions in terms of fatality, heavy injury and accident in order to draw the correct conclusions. For our case study, the definitions of parameters comply with the Eurostat definitions. Actually, it is supposed that "deaths in road accidents are people who were killed outright or who died within 30 days as a result of the accident" and that a serious injury is "an injury for which a person is detained in hospital as an "in-patient" or any of the following injuries whether or not the injured person is detained in hospital" but do not involve the death within the recording period (Odgaard et al. [22]). It should be noted that the analysis intentionally does not include the net benefits for the avoided slight injuries because of the lack in the Eurostat and French and German databases. The following part is dedicated to the presentation of the cost benefit approach in 
transport. The next one is devoted to the definition of the framework whereas the last parts outline the whole level crossing case study and the results.

\section{Economics in transport}

\subsection{The role of the $\mathrm{CBA}$}

In transport, a CBA has to emphasize the best alternative to reach the objectives at lower costs. The difficulty rests on the fact that the decision makers have to make a selection under uncertainty because a few effects are unpredictable (Jokung [16]; Laffont [18]). Moreover, a CBA is not always applicable and the means do not always square with the objectives (Rune [24]). Concretely, the CBA has to highlight the different choices by supplying an economic evaluation from a fault tree analysis and clarify all the costs and benefits to focus on the best option in economic terms. To mint these costs and benefits, two types of techniques are elaborated, especially for the goods which do not enter the merchant sphere. The first method is based on a contingent valuation (Terra [29]), which directly infers a willingness-to-pay or a willingness-to-accept regarding answers to questions of investigations according to several scenarios. The second rests on a hedonic method (Gravel et al. [14]), which consists in observing individual decisions on the market of risk to determine an implicit value of goods. Thus, these two different methods allow the monetary valuation of costs and benefits in order to deter-mine if a project is profitable or not. For the majority of projects in transport, benefits mainly concern avoided accidents and saved lives or injuries (Carsten and Tateb [7]). Within this framework, it is important to understand how the value of human life is estimated.

\subsection{Monetary valuation of human life}

Three methods are used to appreciate the cost of life in transport. Indeed, the value of human life can be based on the means invested to compensate the effects of an accident; this is the method of cost compensation. The human capital approach aims at estimating the updated losses of the society following human damage, and, the willingness to pay or to accept principle seeks to evaluate the satisfaction levels for a sample of individuals in order to estimate a mean value. In transport, this approach can allow the valuation of human life by asking individuals the maximum amount they are willing to pay to benefit from a better safety level. For several years, the suggested value of human life to retain for all the European projects of collective transport has been one and a half million euro (Boiteux [6]; Desaigues and Rabil [11]; Odgaard et al. [22]). However, individuals are considered to be more responsible for their own safety level on roads (LievremontArtinian and Bertel [19]; SNCF [28]), that is the reason why the value of human life for road transport only represents $66 \%$ of the total cost of life, that is to say one million euro. As the LC case study relies on the French and German railway systems, it is necessary to compare the values of human life for the two countries to see if the European common value can be used in the CBA. Thanks to the values 
expressed in purchasing power parity in the table below, we can see that the cost of human life for France and Germany is very close to the European common value, so it can be used in the CBA. The purchasing power parity unit allows the conversion between economic indicators expressed in a national currency and an artificial common currency in order to compare prices between countries.

Table 1: $\quad$ Estimated values of human damage in France and in Germany.

\begin{tabular}{|c|c|c|c|c|}
\hline Country & $\begin{array}{c}\text { Fatality } \\
\left(\boldsymbol{(}_{\mathbf{2 0 0 2}}\right)\end{array}$ & $\begin{array}{c}\text { Severe injury } \\
\left(\boldsymbol{(}_{\mathbf{2 0 0 2}}\right)\end{array}$ & $\begin{array}{c}\text { Fatality } \\
\left(\boldsymbol{(}_{\mathbf{2 0 0 2}} \mathbf{P P P}\right)\end{array}$ & $\begin{array}{c}\text { Severe injury } \\
\left(\boldsymbol{(}_{\mathbf{2 0 0 2}} \mathbf{P P P}\right)\end{array}$ \\
\hline France & $1,617,000$ & 225,800 & $1,548,000$ & 216,300 \\
\hline Germany & $1,661,000$ & 229,400 & $1,493,000$ & 206,500 \\
\hline
\end{tabular}

To comprehend the CBA, the part below is devoted to the presentation of the context and the stakes of the French and German Rail Optimization Safety Analysis (ROSA) project (Ben Aoun et al. [5]; Klinge [17]).

\section{Background}

The ROSA project evolves within the regulatory framework of the Interoperability Directives 96/48/EC (Council Directive 96/48/EC [9]) and 2001/16/EC (Directive 2001/16/EC [10]) through the technical specifications for interoperability (TSI) which claim that "each subsystem or part of a subsystem is covered in order to meet the essential requirements and ensure the interoperability of the trans-European high-speed and conventional rail systems". In spite of technical and scientific progress, railway competitiveness and the rail safety directive 2004/49/CE [8] do not suffice for LCs. Indeed, heavy and constant safety measures have to be implemented to decrease the number of accidents and fatalities especially at "worrying" LCs, i.e. LCs with a high rate of accidents and/or incidents.

Within this framework and in the continuity of the Safer European Level Crossing Appraisal and Technology (SELCAT) project, the Franco-German ROSA project foresees a risk analysis for the two railway systems in order to identify the safety levels of the new railway safety functions and to quickly choose the best safety measures to implement. Therefore, the CBA is essential in the sense that it aims to identify all the possible options and determine the best alternatives in economic terms. Concretely, the ROSA project serves three significant aims: improvement of the understanding of railway safety in Germany and in France, ensuring the profitability of investments, and support the impact assessments for safety target definitions for the European Railway Agency. For doing so, the roles of DB AG (German railway undertaking) and SNCF (French railway undertaking) are vital regarding the definition of safety targets through the preliminary safety analysis of the overall railway systems. Concerning safety, the global French and German railway systems are the object 
of a risk analysis. The aim is to investigate the consequences of the allotment of railway common safety targets in order to at least maintain or improve the actual safety level thanks to the best safety investments. This risk analysis has to take into account the different safety directive groups at risk and introduce, if possible, a risk aversion factor in the calculations through the value of human life according to the willingness-to-pay or to-accept.

\section{The level crossing case study}

Before presenting the LC CBA, it is necessary to briefly define the functioning of a LC in France and in Germany. In France, when a train is approaching the LC, the barriers are supposed to be closed and free of any obstacle. As it is not always true, a classification of the "worrying LC" has been done to improve safety at the most dangerous LCs. In Germany it is different: the train is supposed to be able to stop before an unprotected LC. This supposes a constant attention for the train driver and a good visibility on the road when the train is approaching the LC.

\subsection{Presentation}

First of all, it should be noted that this particular case study obliges the CBA to consider all the possible safety measures capable of enhancing safety on road and on rail. For this, it is necessary to identify the main causes of accidents at LCs, to estimate the potential reduction of accidents and to integrate the past tendencies into the calculations in terms of number of accidents, fatalities and heavy injuries to obtain the correct results. The CBA has to clarify the different technical solutions in order to specify the most efficient safety measure in terms of avoided human damage. By doing so, the CBA will compute all the discounted costs and benefits for all the stakeholders to estimate the three selection criteria inherent to the CBA and to implement the best safety option. Nevertheless, it is necessary to determine the current safety level regarding accidents and human damage in order to compare those data with the estimated ones thanks to linear regression straight lines.

As previously said, the main profits concern saved human lives. In general (Boîteux [6]), human life is estimated at $€ 1,500,000$ for collective transport and at $€ 1,000,000$ for road transport. In the same way, a heavy injury is estimated at $€ 225,000$ for collective transport and at $€ 150,000$ for road transport. As more than $98 \%$ of accidents at LCs in France and in Germany are due to road users' behavior, the value of human life and of heavy injury to be taken into account are consequently those regarding road transport. However, let us recall that the benefits for avoidable slight injuries are not included.

\subsection{Data sources and hypotheses}

The CBA allowed the identification of four different solutions to reach the objectives of enhancing safety at LCs:

- the half-barrier implementation, 
- the LC suppression,

- radar installations on road, and,

- safety campaigns.

According to a SELCAT study, the potential reduction of accidents for a halfbarrier implementation at unprotected LCs is supposed to be $69 \%$ for cross bucks and $45 \%$ for LCs with flashing lights and bells. The effectiveness of an LC suppression is supposed to be $100 \%$ for all LCs. The French experimentation showed that radar implementations between 2003 and 2004 could reduce the number of accidents by $23 \%$ so the effectiveness is supposed to be the same for the two countries (any kind of radar measure is known for Germany). However, the European Railway Agency Guidelines (ERA [13]) claim that the hypotheses have to be checked to maximize the reliability of results. For this reason, regression linear equations for all the parameters are computed in order to integrate the past tendencies into the calculations and estimate the real effects of radars on road. Besides, the CBA is supported to determine the best safety measure for railway so radars are also supposed to be implemented by infrastructure managers in order to benefit from the income of fines in the same time.

This amount is not negligible when we know that the mean cut fine is $€ 90$ and that the mean surcharged fine is $€ 135$ in France. According to the Interdepartmental National Observatory for Road Safety (ONISR) in France, the mean fine observed in 2007 was $€ 65$ for 6,983,650 parking tickets. Thus, the CBA takes into account two cases for the radar safety option: road responsibility and rail responsibility. As the apportionment from these fines income is unknown for Germany, the CBA only considers the first case for Germany, that is to say road responsibility. According to the action plan for road safety (20032010), safety campaigns could reduce the number of accidents by $2,35 \%$ per year over 7 years. This is the first hypothesis regarding the effectiveness of safety campaigns.

Regarding the effectiveness of radar implementations, it is not utopian to think that safety campaigns could also reduce the number of accidents by $23 \%$. This is the second hypothesis. The last hypothesis is based on a report about safety measures (Canadian National Institute for Public Health [21]) which claims that safety campaigns could decrease the number of accidents from $19 \%$ to $26 \%$ so the CBA also takes into account these two extremities. Thus, the economic analysis takes into account the following measures:

- Option $\mathrm{n}^{\circ}$ 1.1: Implementation of a half-barrier (for a potential reduction of accidents of $69 \%$ ),

- Option $\mathrm{n}^{\circ} 1.2$ : Implementation of a half-barrier (for a potential reduction of accidents of $45 \%$ ),

- Option n²: LC suppression,

- Option n 3.1: Radar installations on road (without correction),

- Option n³.2: Radar installations on road (with correction),

- Option n०3.3: Radar installations if costs and a part of benefits come to railways (if the mean fine is $65 €$ ), for France, 
- Option n ${ }^{\circ} 3.4$ : Radar installations if costs and a part of benefits come to railways (if the mean fine is $90 €$ ), for France,

- Option n ${ }^{\circ} 3.5$ : Radar installations if costs and a part of benefits come to railways (if the mean fine is $135 €$ ), for France,

- Option n ${ }^{\circ}$ 4.1: Safety campaigns (for a potential reduction of accidents of $2,35 \%$,

- Option ${ }^{\circ} 4.2$ : Safety campaigns (for a potential reduction of accidents of $19 \%$ ),

- Option n ${ }^{\circ}$ 4.3: Safety campaigns (for a potential reduction of accidents of $23 \%$ ),

- Option n ${ }^{\circ} 4.4$ : Safety campaigns (for a potential reduction of accidents of $26 \%$ ).

For the calculations of the selection criteria, four updating rates are retained in order to test the reliability of the results: $3 \%, 4 \%, 5 \%$ and $8 \% .3 \%$ is the updating rate commonly used in Germany, $8 \%$ in France, $4 \%$ is the reviewed rate in France (HEATCO [15]) and 5\% is the recommended rate for public projects of investments (European Commission [12]). Most of the physical and economic data come from the SNCF for France and from the DB AG for Germany. Tables 2 and 3 give estimations of the profitability of the four safety measures according to the selection criteria in France and Germany

\section{Results and discussion}

The two tables, 2 and 3 shown overleaf sum up the general results of the CBA according to the three selection criteria. The cells in yellow (shaded) show the best economic results. The error message means that the internal rate of return is negative due to the fact that benefits do not cover costs over time. The "senseless" message indicates that the calculation of the IRR is not necessary because there is no cost for railways if radars are implemented on roads. Thus, any other safety measures could be more profitable for rail transport.

As previously said, the updating rate commonly used in CBAs is $8 \%$ in France and 3\% in Germany. Within this framework, a safety measure is profitable only if the net present values are positive, if the benefit to cost ratio is higher than one and if the internal rate of return is higher than the updating rate to be more gainful than a financial investment on the market (Abraham-Frois [1]). These conditions have to be respected at the same time. At first sight, we could think that the most efficient option in France is safety campaigns, as the net present value is widely higher that of the radar option, but the internal rate of return is far from $8 \%$, which is not the case for radar implementations on road. From the railway point of view, if we consider that the updating rate to return for the internal rate of return is the reviewed rate of $4 \%$, the best safety option is still radar implementations but only if the mean fine is $€ 90$ or $€ 135$. In the same way, it seems that the best option is the last one in Germany, but the internal rate of return is lower than $3 \%$. In this case, the best safety option seems to be radar installations on roads but, from the railway point of view, investments should be angle towards safety campaigns. 


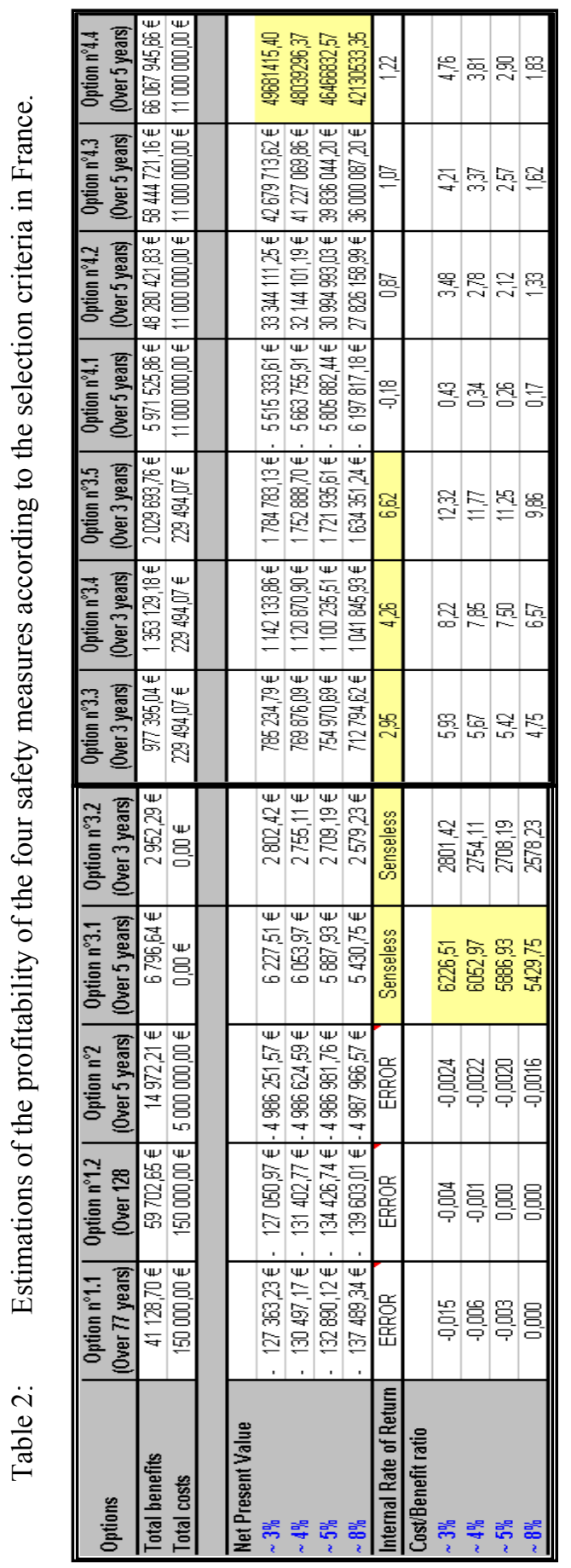




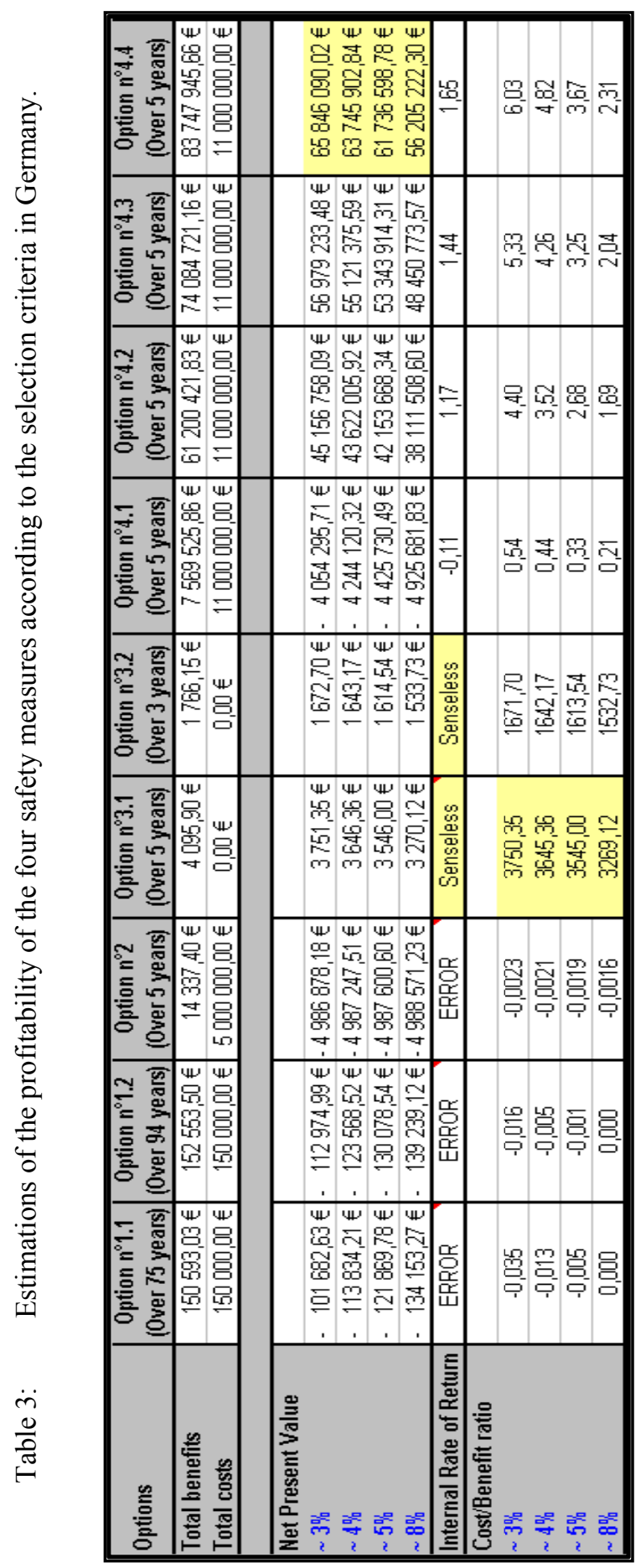




\section{Conclusion}

This paper presents the results of the CBA for LCs within the framework of the rail optimization safety analysis project. To that purpose, we analyzed the railway systems in France and in Germany in order to identify the possible safety options to implement for enhancing safety at LCs. As more than $98 \%$ of accidents at LCs are due the non-respect of the rules of the road, it is not surprising to notice that the best safety measures are without any doubt those which directly act on road users' behavior, such as radar installations on roads and on rail or safety campaigns. Nevertheless, it is important to recall that the aim of the CBA is to determine the best actions to be taken from the railway point of view. This is the reason why the analysis supposed that radar installations could be undertaken by railways and that they could benefit from the same profits as if they were undertaken for road transport.

The economic valuation speaks for itself because one rail radar installation allows a profit estimated at more than two million euro per year in terms of fine incomes. In other words, the fact of implementing only one radar per year allows the saving of one life. However, it is very difficult to include all the effects of a safety option in a CBA (Andrieu [2]). Thus, the results have to be used with caution.

\section{Acknowledgements}

This study is the result of the work for the Deufrako project financed by the National Agency for Research and was supported in part by the ROSA partners.

\section{Reference}

[1] Abraham-Frois G., Political Economics, Economica, 2001.

[2] Andrieu L., de Palma A., Picard N., Risk in Transport Investments, 2006.

[3] Bellavance F., Dionne G., Lebeau M., The Value of a Statistical Life: A Meta-Analysis with a Mixed Effects Regression Model, 2006.

[4] Ben Aoun R., El Koursi E.M., Lemaire E., Rafrafi M., Cost-Benefit Analysis approach in railway sector, Rail Optimisation Safety Analysis, Delivrable 3.1., March 2008.

[5] Ben Aoun R., El Koursi E.M., Lemaire E., How can risk aversion factor characterize choices of economic agents under uncertainty, Symposium on Formal Methods for Automation and Safety in Railway and Automotive Systems, October 2008.

[6] Boîteux M., "Transport: choix des investissements et coût des nuisances", Commissariat Général du Plan, June 2001.

[7] Carsten O.M.J., Tateb F.N., "Intelligent speed adaptation: accident savings and cost-benefit analysis", Accident analysis and prevention, February 2004.

[8] Council Directive 2004/49/EC on Safety on the Community's Railways and amending Council Directive $95 / 18 / \mathrm{EC}$ on the licensing of railway 
undertakings and Directive 2001/14/EC on the allocation of railway infrastructure capacity and the levying of charges for the use of railway infrastructure and safety certification (Railway Safety Directive), Official Journal of the European Union.

[9] Council Directive 96/48/EC of 23 July 1996 on the interoperability of the trans-European high-speed rail system.

[10] Directive 2001/16/EC of the European Parliament and of the Council of 19 March 2001 on the interoperability of the trans-European conventional rail system.

[11] Desaigues B. and Rabl A., Reference values for human life, 1995.

[12] European Commission, "Methodological guideline for cost benefit analyses application", August 2006.

[13] European Railway Agency, Economic Evaluation Methodology Guidelines, March 2006.

[14] Gravel N., Michelangeli A., Trannoy A., "Measuring the social value of local public goods: an empirical analysis within Paris metropolitan area", 2006.

[15] Developing Harmonized European Approaches for Transport Costing and Project Assessment, 2005. For more information, the web site is http://heatco.ier.uni-stuttgart.de/.

[16] Jokung O., Micro economy of the uncertain, Dunod, 2001.

[17] Klinge K., Optimization safety analysis for common railway safety indicators, World Congress on Railway Research, May 2008.

[18] Laffont J.J, Economie de l'incertain, Vol. 2 "Cours de Théorie Microéconomique", Collection "Economie et statistiques avancées", Economica, 1999.

[19] Lievremont-Artinian S. and Bertel D., SNCF, "The management of the risk in the railroad transport", June 1992.

[20] Ministry of the Equipment, Transport, the Accommodation, the Tourism and the Sea, The frame-instruction relative to methods of economic evaluation of big projects of transport infrastructure, May 2005.

[21] National Institutes of Health IT projects, "Cost-benefit analysis evaluation guide", August 2000.

[22] Odgaard T., Kelly C., Laird J., HEATCO Work Package 3: Current practice in project appraisal in Europe, Delivrable1/Vol.1, January 2005.

[23] Rodgers A.B., Leland E.W., "A retrospective benefit-cost analysis of the 1997 stair-fall requirements for baby walkers", Accident analysis and prevention, April 2007.

[24] Rune E., "Cost-benefit analysis of road safety measures: applicability and controversies", Accident analysis and prevention, November 1999.

[25] R. Slovak, E. M. El Koursi, L. Tordai, M. Woods, E. Schneider, SELCAT: Its contribution to European Level Crossing safety, EURAILmag ${ }^{\circ}$. 18, $12 \mathrm{p}, 2008$.

[26] E. M. El Koursi, L. Khoudour, N. Lazarevic, L. Tordai, R. Slovak, 2008. Safer European Level Crossing Appraisal and Technology, "appraisal", 
Workshop 16 May 2007, Actes n¹17, ISSN 0769-0266, Collection Actes INRETS

[27] E. M. El-Koursi, L. Khoudour, S. Impastato, G. Malavasi, S. Ricci, 2008. Safer European Level Crossing Appraisal and Technology, "Technology", Workshop 22nd - 23rd November 2007.

[28] SNCF, "Value of life and coefficient of aversion", May 1994.

[29] Terra S., Direction of the economical studies and the environmental assessment, Good practices guide for the implementation of the method of contingent assessment, May 2005.

[30] Treasury Board of Canada Secretariat, "Benefit-Cost Analysis Guide", 1998. 